\title{
Prospective study on incidence and pattern of congenital abnormalities in a tertiary care hospital in Sri Lanka
}

\author{
*K S Y Perera ${ }^{1}$, Nimesha Chamidani Gamhewage ${ }^{2}$, Medha Weerasekera ${ }^{3}$
}

Sri Lanka Journal of Child Health, 2019; 48(4): 321-325

\begin{abstract}
Background: Congenital abnormalities are defined as structural / functional abnormalities, and/or biochemical-molecular defects present at birth. Common grave anomalies are cardiac defects, neural tube defects and Down syndrome.
\end{abstract}

Objectives: To assess incidence and type of congenital abnormalities in births at Sri Jayewardenepura General Hospital (SJGH).

Method: A prospective study was done at SJGH from March 2015 to end of November 2017 including all the births during that time period. The information was recorded in a pretested data collection sheet. Data was analysed using SPSS statistical software.

Results: Of 10,157 babies born during the study period (both live births and still births) the incidence of congenital abnormalities was $2.6 \%$. Isolated congenital abnormalities were found in $137(1.3 \%)$ babies and multiple congenital abnormalities were found in $96(0.9 \%)$. Fifty one babies belonged to syndromes with an incidence of $0.5 \%$.

Mild, severe and lethal congenital anomalies had incidences of $1.4 \%, 1.2 \%$ and $0.1 \%$ respectively. The commonest anomalies were congenital heart diseases followed by muscular-skeletal system anomalies. Presence of birth defects was

\footnotetext{
${ }^{1}$ Medical officer, Neonatal Intensive care unit, Sri Jayewardenepura General Hospital, Sri Lanka, ${ }^{2}$ Senior Registrar Neonatology and Lecturer in Paediatrics, Department of Paediatrics, Faculty of Medical Sciences, University of Sri Jayewardenepura, Sri Lanka, ${ }^{3}$ Consultant Neonatologist, Sri Jayewardenepura General Hospital, Sri Lanka

*Correspondence: moonstone12345@hotmail.com

orcid.org/ 0000-0002-2296-6055

(Received on 19 February 2019: Accepted after revision on 22 March 2019 \}

The authors declare that there are no conflicts of interest

Personal funding was used for the project.

Open Access Article published under the Creative

Commons Attribution CC-BY (CC) (i)
}

significantly associated with male gender, prematurity and low birth weight.

Conclusions: Incidence of birth defects was $2.6 \%$. The 2 most common anomalies were congenital heart disease and muscular-skeletal system anomalies.

DOI: http://dx.doi.org/10.4038/sljch.v48i4.8826

(Key words: Congenital anomalies, incidence, congenital heart disease, orofacial clefts, Down syndrome)

\section{Introduction}

Congenital abnormalities are defined as structural/ functional abnormalities, and/or biochemicalmolecular defects present at birth ${ }^{1}$. Congenital anomalies led to an estimated 276,000 (7\%) of neonatal deaths worldwide in $2004^{1}$. Common grave anomalies are cardiac defects, neural tube defects and Down syndrome. The causes can be genetic, infectious, nutritional, environmental or multifactorial $^{1}$.

Congenital abnormalities can be classified as:

1. Lethal - defects causing stillbirth or infant death e.g. anencephaly, hypoplastic left heart

2. Severe - defects causing handicap or death without surgical/medical intervention e.g. congenital diaphragmatic hernia, complex congenital heart defects

3. Mild - defects that can be left alone or require surgical/medical intervention but life expectancy is unaffected e.g. polydactyly, undescended testis ${ }^{2}$.

Congenital abnormalities can also be classified as

1. Major - Congenital abnormalities which can be lethal or severe

2. Minor - Anomalies which have no serious medical or cosmetic consequences e.g. pre-auricular tags, syndactyly ${ }^{2}$.

Clinically congenital heart disease (CHD) can be classified as:

1. Life-threatening - structural anomalies where cardiovascular collapse occurs without early treatment e.g. transposition of great arteries, coarctation of aorta. 
2. Clinically significant - structural anomalies which affect cardiac function but where early intervention is not needed. e.g. ventricular septal defect, atrial septal defect, tetralogy of Fallot

3. Clinically insignificant - They are only detectable with echocardiography and require no treatment. e.g. small ventricular septal defect ${ }^{3}$.

Detection and treatment of congenital anomalies consist of neonatal screening programmes such as physical examination of all neonates and screening for congenital hypothyroidism. Treatment of birth defects comprises medical therapy, surgery, rehabilitation and palliative care when appropriate. Other treatment options include in-utero therapy ${ }^{1}$.

The incidence of congenital anomalies has a wide variation globally. In a study conducted in Colombia University, the incidence of congenital malformations was $7.5 \%$. Rate of congenital anomalies was highest among the babies who suffered neonatal deaths, males, non-white infants, babies with birth weight less than $2,500 \mathrm{~g}$ and higher birth order. Muscular-skeletal system and skin were the more frequently affected systems ${ }^{4}$.

In a study conducted by Prashar $\mathrm{N}$ et al, overall incidence of congenital abnormalities was $1.9 \%$. Commonest systems affected were central nervous system $(49.6 \%)$, followed by urinary system (13.8\%). They observed an association between parity and maternal age with the occurrence of congenital anomalies 5 . An incidence of $1.2 \%$ was described in another Indian study ${ }^{6}$. The researchers described a significant association of congenital anomalies with still birth, prematurity and low birth weight. Arjun Singh et al observed an incidence of $1.5 \%$ and the commonest systems involved were muscular-skeletal system and central nervous system. Incidence of birth defects were commoner in babies born via caesarean section, babies with low birth weight and still births ${ }^{7}$. Incidence of birth defects was found to be $2.5 \%$ among live born babies in an Egyptian study. The musculoskeletal system was most commonly affected followed by the central nervous system. Risk factors were identified as consanguinity, maternal malnutrition, a family history of a birth anomaly, low birth weight, prematurity and types of birth ${ }^{8}$. In one of the studies conducted in a tertiary care hospital in Sri Lanka, a prevalence of $4.3 \%$ was described. A higher rate of congenital anomalies was observed among males than among females. Musculoskeletal system was most frequently affected ${ }^{9}$.
Congenital abnormalities are a significant cause of infant deaths. Globally it was among the five most significant contributors of neonatal deaths in 2015, according to $\mathrm{WHO}^{10}$. In 2010 the commonest cause of infant deaths in Sri Lanka was congenital abnormalities, accounting for $43 \%$ infant deaths ${ }^{11}$. Sri Lanka has only recently started to compile a national database of congenital abnormalities. Data on prevalence of congenital abnormalities are available mostly from hospital-based studies.

\section{Objectives}

To assess incidence and type of congenital abnormalities in births at Sri Jayewardenepura General Hospital (SJGH).

\section{Method}

This prospective study was carried out at SJGH for a duration of 2 years and 8 months from March 2015 to end of November 2017. All births at SJGH during the time specified were included. Detailed examination of the babies with anomalies were conducted by Consultant Neonatologist and data recorded in a pretested data collection sheet. The period of gestation, birth weight and gender, type of abnormality and results of confirmatory investigations were recorded. Personal and clinical details of patients collected during study were kept confidential. We assessed the incidence of various categories of congenital anomalies (mild, severe, lethal) in neonates born at SJGH. The study also looked at the associations between anomalies and gender, birth weight, prematurity and types of birth. The study was approved by the Ethics Review Committee of SJGH. Data was analysed using SPSS statistical software.

\section{Results}

Of the 10,157 babies born during the study period 5312 were boys and 4842 were girls and 3 had ambiguous genitalia. Of the total, 268 had congenital anomalies giving an incidence of $2.6 \%$. Mean birth weight of babies included in study was $2.619 \mathrm{~kg}$ and the mean period of gestation was 37 to 40 weeks. Isolated congenital abnormalities were found in $137(1.3 \%)$ babies, while multiple congenital abnormalities were found in $96(0.9 \%)$ babies. Among the babies with abnormalities there were 51 babies belonging to syndromes with an incidence of $0.5 \%$.

The classification of congenital anomalies is shown in Table 1 and the pattern of congenital anomalies is shown in Table 2 . 
Table 1: Classification of congenital anomalies

\begin{tabular}{|l|c|c|}
\hline \multicolumn{1}{|c|}{ Severity } & Number of babies affected & Incidence \\
\hline Mild & 140 & $1.37 \%$ \\
\hline Severe & 119 & $1.17 \%$ \\
\hline Lethal & 09 & $0.08 \%$ \\
\hline
\end{tabular}

Table 2: Pattern of congenital anomalies

\begin{tabular}{|l|c|c|}
\hline \multicolumn{1}{|c|}{ Abnormality } & Number of babies & Incidence per 10,000 births \\
\hline Central nervous system & 07 & 6.89 \\
\hline Anencephaly & 02 & 1.96 \\
\hline Hydrocephalus & 02 & 1.96 \\
\hline Myelomeningocele & 01 & 0.98 \\
\hline Corpus Callosum Agenesis & 02 & 1.96 \\
\hline Eye/ear/neck & 15 & 14.76 \\
\hline Cardio Vascular System & 127 & 125 \\
\hline Clinically non-significant heart disease & 106 & 104.36 \\
\hline Clinically significant heart disease & 31 & 30.52 \\
\hline Lethal heart disease & 03 & 2.95 \\
\hline Pulmonary Hypoplasia & 04 & 3.98 \\
\hline Orofacial clefts & 15 & 14.7 \\
\hline Digestive system & 05 & 4.9 \\
\hline Trachea oesophageal fistula & 02 & 1.96 \\
\hline Hirschsprung disease & 01 & 0.98 \\
\hline others & 02 & 1.96 \\
\hline Genital and urinary system & 25 & 24.6 \\
\hline Ambiguous genitalia & 03 & 2.95 \\
\hline Hypospadias & 09 & 8.86 \\
\hline Hydronephrosis & 04 & 3.98 \\
\hline Renal hypoplasia & 01 & 0.98 \\
\hline Micropenis & 05 & 4.92 \\
\hline Polycystic kidney & 02 & 1.96 \\
\hline Posterior urethral valve & 02 & 1.96 \\
\hline Absent testis & 03 & 2.95 \\
\hline Muscular-skeletal system & 56 & 55.1 \\
\hline limb deformities (including talipes) & 43 & 42.33 \\
\hline Polydactyly and syndactyly & 08 & 7.87 \\
\hline Diaphragmatic hernia & 10 & 9.84 \\
\hline Haemangioma & 02 & 1.96 \\
\hline Syndromic babies & 51 & 50.2 \\
\hline
\end{tabular}

The commonest syndrome identified was Down syndrome (16 babies, with an incidence of $0.15 \%$ ). Two babies each having Treacher-Collins and Klippel Trenaunay syndromes were recognised. Pierre Robins, Sturge Weber, Carpenter, Osteogenesis imperfecta and albinism were recognised in 1 baby each. Karyotyping was done in 26 babies, who were lost to follow up.

In the present study, presence of congenital abnormalities is significantly associated with gender, maturity and birth weight. Whilst $3.2 \%$ of boys had congenital abnormalities, only $2.2 \%$ of girls were identified as having defects. Birth defects were commonest in extremely low birth weight (ELBW) babies. Incidence of birth anomalies among babies with normal birth weight, low birth weight, very low birth weight and ELBW were, $2 \%, 4.4 \%, 24.4 \%$ and $30.2 \%$ respectively. Term babies had an incidence of $1.9 \%$ of birth defects, whereas the incidence increased as the maturity decreased. Incidence of birth defects among babies born moderate to late preterm, very preterm and extremely preterm were $4.2 \%, 26.8 \%$ and $38.5 \%$ respectively. However, there was no significant association between stillbirth and congenital abnormalities.

Association of the type of birth with congenital anomalies is shown in Table 3. Association of gender with congenital anomalies is shown in Table 4. Association of birth weight with congenital anomalies is shown in Table 5 . Association of maturity of the babies with congenital anomalies is shown in Table 6. 
Table 3: Association of type of birth with congenital anomalies

\begin{tabular}{|l|c|c|c|}
\hline \multicolumn{1}{|c|}{ Type of birth } & $\begin{array}{c}\text { Number of babies without } \\
\text { abnormalities }\end{array}$ & $\begin{array}{c}\text { Number of babies with } \\
\text { abnormalities }\end{array}$ & Total \\
\hline Live birth & 9850 & 265 & 10115 \\
\hline Still birth & 39 & 3 & 42 \\
\hline
\end{tabular}

$\chi^{2}=3.3308, p=0.0679$

Table 4: Association of gender with congenital anomalies

\begin{tabular}{|l|c|c|c|}
\hline \multicolumn{1}{|c|}{ Gender of baby } & $\begin{array}{c}\text { Number of babies } \\
\text { without abnormalities }\end{array}$ & $\begin{array}{c}\text { Number of babies with } \\
\text { abnormalities }\end{array}$ & Total \\
\hline Male & 5149 & 163 & 5312 \\
\hline Female & 4739 & 103 & 4842 \\
\hline
\end{tabular}

$X 2=8.789 p<0.003$

Table 5: Association of birth weight with congenital anomalies

\begin{tabular}{|l|c|c|c|}
\hline \multicolumn{1}{|c|}{ Birth weight } & $\begin{array}{c}\text { Number of babies } \\
\text { without abnormalities }\end{array}$ & $\begin{array}{c}\text { Number of babies with } \\
\text { abnormalities }\end{array}$ & Total \\
\hline$>2500 \mathrm{~g}$ & 8541 & 175 & 8716 \\
\hline $2500-1500 \mathrm{~g}$ & 1249 & 57 & 1306 \\
\hline $1500-1000 \mathrm{~g}$ & 62 & 20 & 82 \\
\hline$<1000 \mathrm{~g}$ & 37 & 16 & 53 \\
\hline
\end{tabular}

$X 2=311.585 \quad p<0.00001$

Table 6: Association of maturity of the babies with congenital anomalies.

\begin{tabular}{|l|c|c|c|}
\hline \multicolumn{1}{|c|}{ Maturity in weeks } & $\begin{array}{c}\text { Number of babies } \\
\text { without abnormalities }\end{array}$ & $\begin{array}{c}\text { Number of babies with } \\
\text { abnormalities }\end{array}$ & Total \\
\hline $37-40$ & 9121 & 175 & 9296 \\
\hline $32-37$ & 657 & 29 & 686 \\
\hline $28-32$ & 109 & 40 & 149 \\
\hline$<28$ & 16 & 10 & 26 \\
\hline$X 2=523.0457 p<0.00001$ & \multicolumn{2}{|}{}
\end{tabular}

\section{Discussion}

Our study demonstrates a higher incidence of birth defects compared to Indian studies which describe rates ranging from $1.2 \%-1.8 \%{ }^{5,6}$. The observed higher rate could be due to increased referrals of mothers with an abnormal fetus to SJGH and high rate of identification. However, it is in accordance with rates observed in European surveillance of congenital anomalies, which describes a prevalence of 255.61 per 10,000 births ${ }^{11}$. A study conducted in Mahamodara hospital evaluating births over a 6month period found a prevalence of $4.3 \%$ which is higher than ours.

In most of the studies conducted elsewhere in the world, the most commonly affected system was the muscular-skeletal system ${ }^{3,6,7,8}$. In contrast, the commonest defect identified in our study is CHD. Our incidence of CHD is higher when compared to that of western countries where it ranges from 3-12 per 1000 live births ${ }^{12}$.

In the current study, the incidence of congenital anomalies increased as the birth weight decreased and also increased with prematurity, which is statistically significant. This association of low birth weight and congenital defects has been demonstrated in other studies as well ${ }^{5,6,7}$. Association of birth defects with prematurity is well documented in previous studies ${ }^{5,7}$. Although many studies have documented an association of birth defects with still birth, it was not apparent in our study ${ }^{5,6}$. In previous studies male gender has been associated with increased incidence of birth defects $^{3,8}$. In our study too, birth defects were more prevalent among boys. As there can be a regional difference in the types of birth defects and causative factors, we need to conduct island wide studies to identify patterns and associations of congenital defects

\section{Conclusions}

Incidence of birth defects was $2.6 \%$. The 2 most common anomalies were congenital heart disease and muscular-skeletal system anomalies. Statistically significant association was observed between birth defects and prematurity, low birth weight and male gender. 


\section{References}

1. World Health Organization. Birth Defects - Report by the Secretariat. Sixty Third World Health Assembly - Provisional agenda item 11.7. 2010; A63/10:1-7.

2. Czeizel AE. Birth defects are preventable. International Journal of Medical Sciences 2005; 2(3): 91-2.

https://doi.org/10.7150/ijms.2.91

PMid: 16007259 PMCid: PMC1168872

3. Yun SW. Congenital heart disease in the newborn requiring early intervention. Korean Journal of Pediatrics 2011; 54(5):183-91.

https://doi.org/10.3345/kjp.2011.54.5.183

PMid: 21829408 PMCid: PMC3145901

4. McIntosh R, Merritt KK, Richards MR, Samuels MH, Bellows MT. The Incidence of congenital malformations: a study of 5,964 pregnancies. Pediatrics 1954; 14(5): 505-22.

PMid: 13214966

5. Prashar N, Gupta S, Thakur R, Sharma P, Sharma G. A study of incidence of congenital anomalies in newborn: a hospital based study. International Journal of Research in Medical Sciences 2016; 4(6):2050-3.

https://doi.org/10.18203/23206012.ijrms2 0161758

6. Gandhi MK, Chaudhari UR, Thakor N. A study on incidence of congenital anomalies in new borns and their association with fetal factors: a prospective study. International Journal of Research in Medical Sciences 2016; 4(4):1200-3.

https://doi.org/10.18203/23206012.ijrms2 0160809
7. Singh A, Gupta RK. Pattern of congenital anomalies in newborn: A hospital based prospective study. JK Science 2009; 11(1):34-6.

8. El Koumi MA, Al Banna EA, Lebda I. Pattern of congenital anomalies in newborn: A hospital-based study. Pediatric Reports 2013; 5(1): e5. https://doi.org/10.4081/pr.2013.e5 PMid: 23667734 PMCid: PMC3649744

9. Fernando S, Bandara T, Sathanantharajah R, Withanaarachchi K. Pattern of clinically recognisable congenital malformations in babies born in a tertiary referral centre in Sri Lanka. Ceylon Medical Journal 2014; 59(4):132-5. https://doi.org/10.4038/cmj.v59i4.7866 PMid: 25556410

10. WHO | Congenital anomalies [Internet]. WHO. 2016. Available from: http:/www.who.int/mediacentre/factsheet s/fs370/en/

11. European Commission. JRC-EUROCAT Central Registry. Italy: Institute for Health and Consumer Protection, DG Joint Research Centre (JRC). Available from: http:/www.eurocatnetwork.eu/accessprev alencedata/prevalencetable

12. Hoffman JI. Incidence of congenital heart disease: I. Postnatal incidence Pediatric Cardiology 1995; 16(3):103-13. https://doi.org/10.1007/BF00801907 PMid: 7617503 